\title{
Taura syndrome virus from Belize represents a unique variant
}

\author{
Heidi S. Erickson ${ }^{1,2}$, Bonnie T. Poulos ${ }^{1, *}$, Kathy F. J. Tang ${ }^{1}$, Deborah Bradley-Dunlop ${ }^{1}$, \\ Donald V. Lightner ${ }^{1}$
}

\author{
${ }^{1}$ Aquaculture Pathology Laboratory, Department of Veterinary Science and Microbiology, The University of Arizona, \\ 1117 East Lowell Street, Tucson, Arizona 85721, USA
}

${ }^{2}$ Present address: Pathogenetics Unit, Laboratory of Pathology and Urologic Oncology Branch, Center for Cancer Research, National Cancer Institute, National Institutes of Health, Bethesda, Maryland 20892-4605, USA

\begin{abstract}
A Taura syndrome virus (TSV) isolate from cultured Penaeus vannamei grown in Belize, Central America was characterized and shown to be a unique isolate. Mortality rates in laboratory infections of specific pathogen-free (SPF) P. vannamei, reactivity of the virus with monoclonal antibody (MAb) $1 \mathrm{~A} 1$ and phylogenetic analysis demonstrated that the Belize isolate (BLZ02TSV) is a new variant of TSV. The Hawaiian 1994 TSV isolate (HI94TSV, GenBank AF277675) was used as the reference isolate for these studies. Laboratory infections of SPF P. vannamei with BLZ02TSV demonstrated higher mortalities and earlier onset of mortalities compared to infections with HI94TSV. Shrimp tissues infected with BLZ02TSV reacted with a TSV-specific gene probe by in situ hybridization and were positive by RT-PCR using TSV diagnostic primers, thus indicating that the isolate was TSV. However, Western blot analysis and immunohistochemistry using MAb 1A1 demonstrated that BLZ02TSV did not react with the antibody, suggestive of changes in the VP1 region of the genome that codes for the polypeptide to which MAb 1 A1 binds. Phylogenetic analysis of a $1.3 \mathrm{kbp}$ fragment of the TSV VP1 capsid region revealed that BLZ02TSV represents a distinct group among more than 29 isolates of TSV studied thus far. This research demonstrates that BLZ02TSV is a unique isolate of TSV and reiterates a problem related to the use of MAb $1 \mathrm{~A} 1$ for detection of TSV in clinical specimens.
\end{abstract}

KEY WORDS: Taura syndrome virus $\cdot$ Belize $\cdot$ Monoclonal antibody 1A1

Resale or republication not permitted without written consent of the publisher

\section{INTRODUCTION}

Taura syndrome (TS), first recognized in Ecuador affecting Penaeus vannamei (Jimenez 1992, Lightner et al. 1995), is now known to occur in most shrimpfarming countries in the Americas, and recently has spread to Taiwan, China, Thailand and Indonesia with the importation of $P$. vannamei for shrimp culture (Chien et al. 1999, Tu et al. 1999, Yu \& Song 2000, Lien et al. 2002, D. V. Lightner pers. comm.). Concomitant with the rapid spread of disease among shrimp populations is the possibility of genetic variations occurring within the viral genome (Alday de Graindorge 2003). Indeed, during 1999 through 2000, reports from the industry indicated that Taura syndrome virus (TSV) was causing significant mortalities in $P$. stylirostris, a penaeid species once believed refractory to acute TS disease (Erickson et al. 2002, Robles-Sikisaka et al. 2002). Also, during 2001 through 2002, the shrimp industry reported on TS epizootics in Belize, Central America, of a severity not seen in western penaeid aquaculture since the initial TS epizootics (Rosenberry 2002).

TSV, the etiologic agent of TS, is a single stranded RNA virus recently classified as a species in the genus Cripavirus within the family Dicistroviridae (Bonami et al. 1997, Mayo 2002a,b). Mari et al. (2002) sequenced the Hawaiian isolate of TSV (HI94TSV) and determined that the genome is 10205 bases in length and identified the positions of the coding regions for the capsid proteins VP1 (55 kDa), VP2 (40 kDa) and VP3 (24 kDa) by 
direct $\mathrm{NH}_{2}$-terminal amino acid sequencing of the polypeptides (Mari et al. 2002; GenBank AF277675). The only commercially available monoclonal antibody (MAb) to TSV, designated MAb 1A1 (DiagXotics), recognizes an antigenic epitope within VP1 (Poulos et al. 1999). Erickson et al. (2002) examined 4 selected TSV isolates from the US and Mexico and demonstrated that there were differences in the ability of 1 of the isolates to react with TSV-specific MAb 1A1. In another study, 2 isolates of TSV from Mexico and Nicaragua also failed to react with MAb 1A1 in paraffin-embedded sections (Robles-Sikisaka et al. 2002). In both studies, the coat protein region of the virus was implicated in the serological differences, which is reasonable since the MAb was shown to react specifically with VP1 by Western blot analysis (Poulos et al. 1999).

Reported here are studies comparing the TSV isolate from Belize (BLZ02TSV) with the reference isolate from Hawaii (HI94TSV). In laboratory bioassay studies, the BLZ02TSV isolate appeared to be more virulent than the reference HI94TSV isolate, supporting industry reports of increased virulence of the BLZ02TSV isolate. The BLZ02TSV isolate was shown to react with the diagnostic TSV primer set in RT-PCR and to yield strong positive signals using the TSV-specific gene probe in the in situ hybridization test. Significantly, the BLZ02TSV isolate failed to react in a Western blot or by immunohistochemistry (IHC) using MAb 1A1. Sequencing and phylogenetic analysis of the VP1 region indicates that BLZ02TSV is distinct from other isolates of TSV studied to date. These findings demonstrate that the isolate from Belize is distinct from the reference isolate and should be classified as a unique variant which displays increased virulence and shows no reactivity to MAb $1 \mathrm{~A} 1$ by Western blot or IHC.

\section{MATERIALS AND METHODS}

Shrimp. Specific pathogen-free (SPF) Kona stock Penaeus vannamei were obtained from the Oceanic Institute's SPF breeding program in Hawaii and were used for generation of TSV and for laboratory bioassays (Wyban et al. 1992, Lotz 1997). The shrimp were reared and maintained at the University of Arizona Aquaculture Pathology Laboratory (UAZAPL) according to the protocol of White et al. (2002). Shrimp taxonomy used in this paper is according to Holthius (1980).

Virus isolates. The viral materials used in these studies were originally collected from Hawaii in 1994 (HI94TSV) and Belize, Central America in 2002 (BLZ02TSV). The viral isolates from Hawaii and Belize were both purified from Penaeus vannamei. Routine histopathology with hematoxylin and eosin-phloxine (H\&E) staining was used to identify TS in the original isolates (Lightner et al. 1995). The diagnosis was confirmed using in situ hybridization with TSV-specific gene probes (Mari et al. 1998).

Bioassays. Experimental quantities of the viruses were prepared and bioassays were performed using SPF Penaeus vannamei (Kona stock) either by per os or injection exposure with infected tissue preparations according to standard methods (Hasson et al. 1995, White et al. 2002). Minced tissues for per os bioassays were fed at a rate of $10 \%$ of the total body weight of the shrimp for 3 consecutive days. Tissue homogenate for injection was prepared using $1 \mathrm{~g}$ infected tissue $5 \mathrm{ml}^{-1}$ of Tris-NaCl buffer (pH 7), and then diluted 1:10 or $1: 20$ in $2 \%(\mathrm{w} / \mathrm{v})$ sterile saline; 10 or $20 \mu \mathrm{l}$, respectively were injected $\mathrm{g}^{-1}$ shrimp. Moribund shrimp were collected for histopathology after fixation in Davidson's alcohol-formalin-acetic acid (AFA) or for virus purification after freezing the tissues at $-70^{\circ} \mathrm{C}$.

Histology. Shrimp preserved in Davidson's AFA were processed for histopathology and observed by light microscopy according to the procedures of Bell \& Lightner (1988).

In situ hybridization. Davidson's AFA-fixed, paraffinembedded shrimp from BLZ02TSV infection used for histology and IHC were also evaluated by in situ hybridization (ISH) utilizing digoxigenin-labeled TSVspecific gene probes P15 and Q1 (Mari et al. 1998).

Virus purification and electron microscopy. Viral isolate purification was conducted according to the procedure of Bonami et al. (1997). Viral preparations were examined by transmission electron microscopy (TEM) using $2 \%$ phosphotungstic acid as the negative stain and tobacco mosaic virus as the calibrator for size determinations (Bonami et al. 1990).

Antibodies. Mouse anti-TSV, MAb 1A1, was used as supernatant fluid from hybridoma cells maintained at the UAZ Aquaculture Pathology Laboratory. Mouse polyclonal antibody (PAb) raised against TSV was produced as described by Poulos et al. (1999). Secondary antibody for detection was a goat anti-mouse IgG (H\&L) $\mathrm{Fab}_{2}$-alkaline phosphatase conjugated polyclonal antibody (Zymed Laboratories) diluted 1:500 before use.

IHC on fixed sections. Moribund shrimp, experimentally infected with BLZ02TSV, were fixed and paraffin-embedded according to standard methods (Bell \& Lightner 1988). IHC was performed according to the protocol of Poulos et al. (2001) using MAb 1A1 as the primary antibody. The slides were examined by light microscopy for the presence of a blue-black precipitate in the cytoplasm of TSV infected cells.

Sodium dodecyl sulfate-polyacrylamide gel electrophoresis (SDS-PAGE). Laemmli buffer (Laemmli 1970) containing $10 \mathrm{M}$ urea was used to denature the structural proteins of individual purified TSV isolates prior 
to separation by SDS-PAGE. Gels were either silver stained (Nielsen \& Brown 1984) or electro-transferred to a polyvinylidene difluoride (PVDF) membrane for amino acid (aa) sequencing or nitrocellulose for Western blotting. Transferred proteins were visualized using $0.1 \%$ Coomassie blue (Matsudaira 1987) or $0.5 \%$ Ponceau red (Nakamura et al. 1985).

Western blot analysis. The Western blot assay was performed by reacting the nitrocellulose membrane with mouse anti-TSV PAb (diluted 1:500) or with MAb 1A1 (undiluted) as the primary antibody and developed according to the protocol described by Poulos et al. (2001). Hybridoma cell culture medium was used as a negative control for the primary antibody.

Protein sequencing. Proteins separated on a $10 \%$ SDS-PAGE gel were transferred to an Immobilon-P ${ }^{S Q}$ PVDF membrane $(0.2 \mu \mathrm{m}$ pore size). The amino termini $\left(\mathrm{NH}_{3}{ }^{+}\right)$of each viral protein were sequenced out for 12 cycles at the UAZ Laboratory for Protein Sequencing and Analyses using an ABI 477A pulsed-liquid protein sequencer (Applied Biosystems).

RT-PCR of purified TSV. The diagnostic TSV-specific oligonucleotide primers that amplify a $231 \mathrm{bp}$ region of the TSV genome were used to confirm the presence of TSV using $1.0 \mu \mathrm{l}$ of each purified TSV preparation as the template (Nunan et al. 1998, OIE 2003). In order to amplify the entire VP1, VP2 and VP3 structural proteincoding regions of the TSV genomes, 6 additional TSVspecific oligonucleotides were developed from the published sequence for Hawaii TSV (GenBank AF277675) based on the starting location of each VP coding region (Mari et al. 2002) (Table 1). For amplification of the VP1, VP2 and VP3 coding regions, the Sigma ${ }^{\circledR}$ enhanced avian RT-PCR kit (Sigma-Aldrich) was utilized and a 1-step RT-PCR amplification of VP1, VP2 and VP3 from purified TSV isolates followed the manufacturer's protocol. Briefly, the RNA template and all the reagents were combined and reverse-transcription was allowed to proceed at $50^{\circ} \mathrm{C}$ for $45 \mathrm{~min}$, followed by $95^{\circ} \mathrm{C}$ for $5 \mathrm{~min}$. After reverse-transcription, PCR was allowed to proceed according to the following profile: reactions were amplified for 40 cycles using denaturation at $95^{\circ} \mathrm{C}$ for $1 \mathrm{~min}$, annealing at $60^{\circ} \mathrm{C}$ (VP1), $50.6^{\circ} \mathrm{C}$ (VP2) or $68^{\circ} \mathrm{C}$ (VP3) for $45 \mathrm{~s}$, and extension at $72^{\circ} \mathrm{C}$ for $1.5 \mathrm{~min}$. A final extension at $72^{\circ} \mathrm{C}$ for $5 \mathrm{~min}$ followed the last cycle of each PCR profile. RT-PCR products were visualized by standard agarose gel electrophoresis.

Nucleotide sequencing of capsid coding regions. TSV nucleotide sequence data for VP1, VP2 and VP3 coat proteins of BLZ02TSV and VP2 and VP3 of HI94TSV were obtained by sequencing the 1303, 1042, and $671 \mathrm{bp}$ RT-PCR products, respectively, at the UAZ Genomic Analysis and Technology Core on an ABI PRISM ${ }^{\circledR}$ 377 DNA sequencer with 'XL' upgrades (Applied Biosystems). VP1 from HI94TSV (GenBank AF510518) had been sequenced previously (Erickson et al. 2002).

\section{RESULTS}

\section{Histological, in situ hybridization and immunohistochemical analysis of BLZ02TSV}

Histological analysis of moribund shrimp infected with the Belize isolate BLZ02TSV demonstrated pathognomonic acute phase TSV lesions characterized by the classic 'peppered or buckshot appearance' in the cuticular epithelium (Lightner et al. 1995) (Fig. 1A). The disease status of these shrimp (data not shown) was confirmed by standard RT-PCR using the TSV diagnostic primer set in Table 1. Further diagnostic testing also confirmed that the Belize isolate was TSV, but was not identical to the HI94TSV reference isolate. A comparison of serial tissue sections of BLZ02TSV-infected shrimp processed for ISH and IHC demonstrated that this isolate could be detected by routine ISH with TSV-specific gene probes P15 and Q1 (Fig. 1B), but could not be detected by IHC with TSV MAb 1A1 (Fig. 1D), although the positive control tissue (HI94) included in the assay was reactive with MAb $1 \mathrm{~A} 1$ (Fig. $1 \mathrm{C}$ ).

\section{TEM confirmation of BLZ02TSV isolate}

Virions purified from the Belize isolate were examined by TEM (data not shown) and their size and shape were determined to be consistent with virions purified from HI94TSV-infected tissues. Size analysis using tobacco mosaic virus as the calibrator demonstrated that 

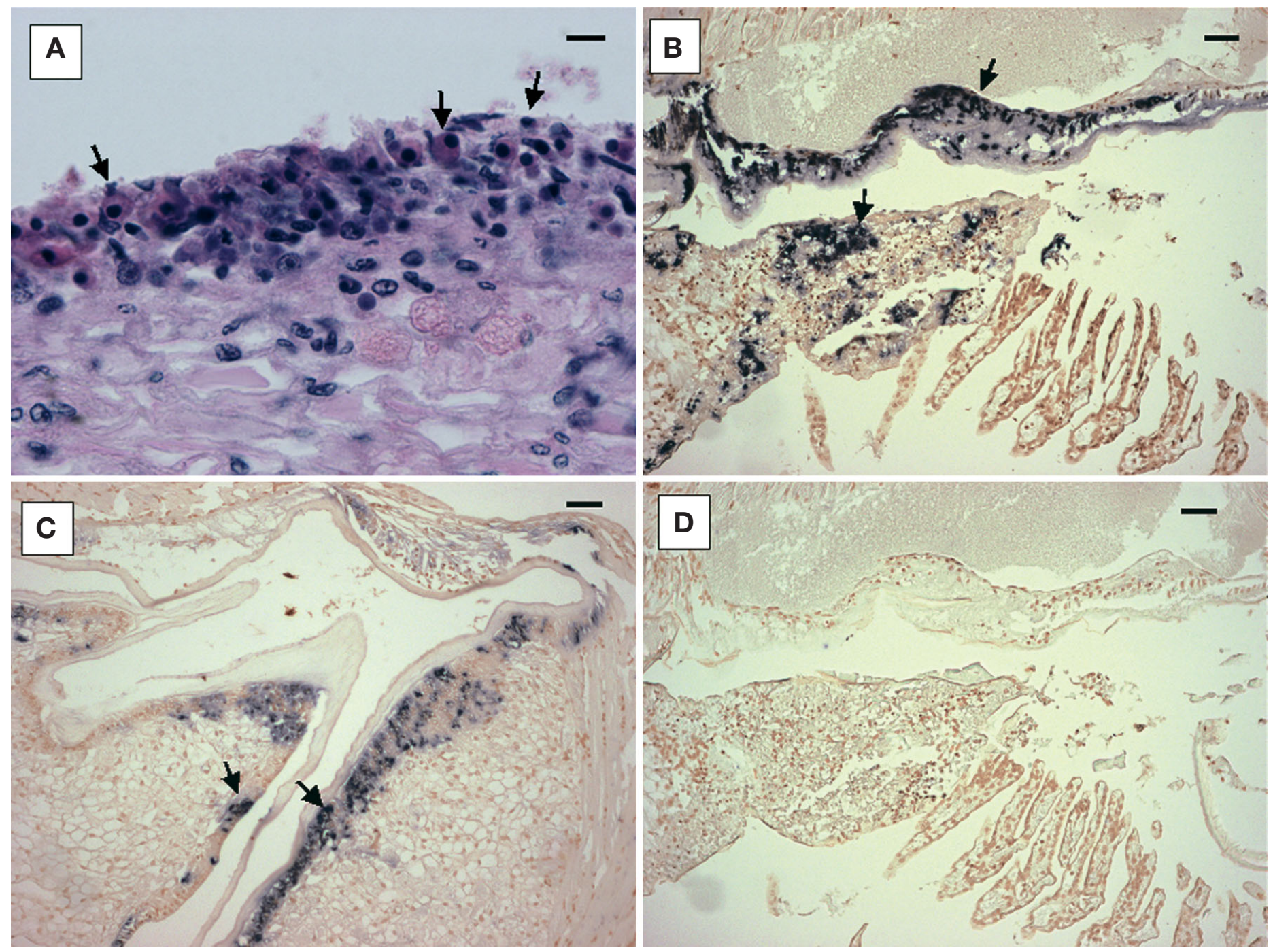

Fig. 1. Penaeus vannamei. (A) Histological section from a BLZ02TSV-infected juvenile stained with hematoxylin and eosin (H\&E); dorsal cuticular epithelium of carapace shows a lesion with cells displaying pyknotic nuclei and increased eosinophilic cytoplasm typical of Taura syndrome virus (TSV) lesions, giving area 'peppered' or 'buckshot' appearance; black arrows indicate examples of pyknotic nuclei in cells with highly eosinophilic cytoplasm. Scale bar $=50 \mu \mathrm{m}$. (B) Section of BLZ02TSV-infected gill and adjacent tissues analyzed by in situ hybridization using gene probes P15 and Q1 in multifocal lesions located primarily in cuticular epithelium; black arrows indicate positive reaction to TSVspecific gene probes. Scale bar $=20 \mu \mathrm{m}$. (C) Section of stomach of HI94TSV-infected shrimp used as positive control in immunohistochemical reaction with MAb 1A1; black arrows indicate positive reaction to TSV-specific monoclonal antibody located primarily in cuticular epithelium of the organ. Scale bar $=20 \mu \mathrm{m}$. (D) Section consecutive to section in (B) of BLZ02TSV-infected shrimp tissue analyzed by immunohistochemistry with MAb 1A1; TSV lesions detected by gene probes in (B) are not detected by MAb 1A1. Scale bar $=20 \mu \mathrm{m}$

the average size of the BLZ02TSV virus particles was $32.693 \pm 1.834 \mathrm{~nm}$ compared to the average size of the HI94TSV virus particles that was $31.485 \pm 1.187 \mathrm{~nm}$.

\section{Bioassays of BLZ02TSV and HI94TSV}

Because of industry reports indicating that the BLZ02TSV isolate was causing higher mortalities than seen previously with TSV, bioassays were con- ducted to compare the disease course of the infection with that due to the reference HI94TSV isolate. Both injection and per os bioassays were performed using SPF Penaeus vannamei (Kona stock). Table 2 shows the results of 8 different bioassays performed from 2002 to 2004 comparing BLZ02TSV and HI94TSV infections. Since there are no known cell culture systems that support the growth of TSV (Pantoja et al. 2004), it was not possible to titer the inoculum preparations that were used. However, the minced and 
Table 2. Penaeus vannamei. Bioassay results of 8 experiments comparing onset and duration of mortality in shrimp (Kona stock) fed or injected shrimp tissues infected with BLZ02TSV or HI94TSV. Duration of each experiment was 14 or $15 \mathrm{~d}$

\begin{tabular}{|c|c|c|c|c|c|c|c|}
\hline \multirow[t]{2}{*}{ Method } & \multirow{2}{*}{$\begin{array}{l}\text { Avg. wt } \\
\text { (g) }\end{array}$} & \multicolumn{3}{|c|}{$\longrightarrow$ BLZ02TSV isolate - } & \multicolumn{2}{|c|}{$\longrightarrow$ HI94TSV isolate } & \multirow[b]{2}{*}{ Mortality (\%) } \\
\hline & & Mortality period & Survivors (n) & Mortality (\%) & Mortality period & Survivors (n) & \\
\hline Per os & 0.5 & Days $2-5$ & $0 / 20$ & 100 & Days 2-6 & $5 / 20$ & 75 \\
\hline Per os & 0.75 & Days $4-6$ & $7 / 20$ & 65 & Days $6-9$ & $8 / 20$ & 60 \\
\hline Per os & 2.0 & Days $2-4$ & $0 / 20$ & 100 & Days $3-7$ & $4 / 20$ & 80 \\
\hline Per os & 1.5 & Days $4-6$ & $2 / 20$ & 90 & Days $3-7$ & $14 / 20$ & 30 \\
\hline Injection & 0.75 & Days $1-2$ & $1 / 20$ & 95 & Days $2-6$ & $8 / 20$ & 60 \\
\hline Injection & 2.0 & Days $1-5$ & $0 / 20$ & 100 & Days $2-6$ & $6 / 20$ & 70 \\
\hline Injection & 5.0 & Days $2-7$ & $1 / 10$ & 90 & Days $2-6$ & $5 / 10$ & 50 \\
\hline Injection & 1.0 & Days $1-3$ & $0 / 10$ & 100 & Days 2-6 & $4 / 10$ & 60 \\
\hline
\end{tabular}

homogenized tissues were prepared using shrimp that were infected at a Grade 3 to 4 level, as assessed by histology. The results indicate that in infections due to BLZ02TSV, mortalities tend to occur earlier (in 5 of the 8 bioassays performed) and result in fewer survivors (in 8 of the 8 bioassays) than with infections due to HI94TSV.

\section{SDS-PAGE analysis}

By SDS-PAGE analysis, BLZ02TSV appeared similar to the HI94TSV isolate (Fig. 2A). The silver stained gel demonstrated that the virus preparations of HI94TSV and BLZ02TSV contained similar amounts of protein and these preparations were used to prepare the membranes for Western blot analysis.

\section{Antigenic reactivity by Western blot and immunohistochemistry}

MAb 1A1 reacts with VP1 of the HI94TSV isolate (Poulos et al. 2001). However, no reaction was seen with MAb 1A1 when reacted with BLZ02TSV, and the reaction of the mouse PAb with BLZ02TSV was much weaker than the reaction seen with HI94TSV (Fig. 2C). Comparison of the bands in the parallel silver stained SDS-PAGE gel (Fig. 2A) and Ponceau red staining of the membrane after electro-transfer (Fig. 2B) demonstrated that the concentrations of the transferred polypeptides in the BLZ02TSV and HI94TSV isolates were similar; therefore, the lack of reactivity with MAb 1A1 was not due to less protein in the preparation. This observation that MAb 1A1 does not react to BLZ02TSV in Western blot was corroborated by the lack of reac-
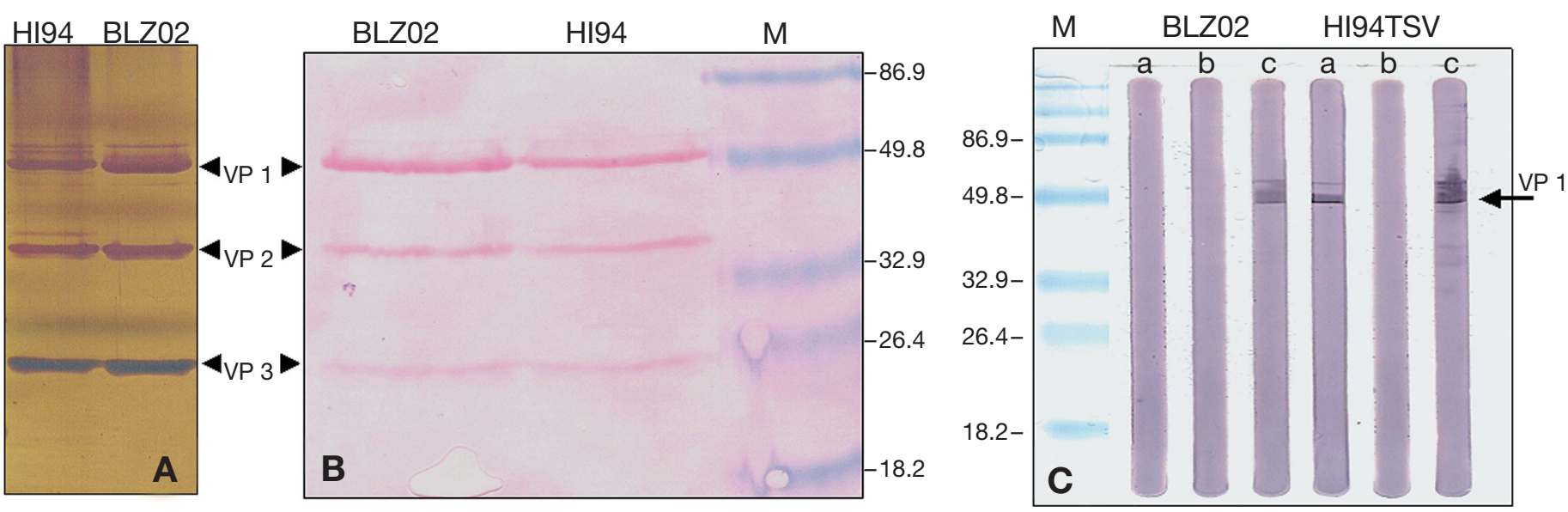

Fig. 2. SDS-PAGE and Western blot analysis of BLZ02TSV isolate compared with HI94TSV isolate. (A) $12 \%$ polyacrylamide gel stained with silver stain; TSV isolates indicated above lanes, viral proteins on right side of gel. (B) Viral proteins from SDS-PAGE run simultaneously with gel that was silver-stained were transferred to nitrocellulose and stained with Ponceau red to demonstrate approximately equal amounts of proteins from each isolate; M: pre-stained molecular weight marker with molecular masses shown on right side of membrane $(\mathrm{kDa})$. (C) Transferred proteins were reacted with MAb 1A1 (Lanes a), hybridoma growth medium (Lanes b) or mouse anti-TSV polyclonal antibody (PAb) (Lanes c); PAb reacted with both TSV isolates, but MAb 1A1 reacted only with HI94TSV isolate; molecular masses of transferred pre-stained marker (Lane M) are shown on left side of gel (kDa) 
tivity with BLZ02TSV in IHC using MAb 1A1 (Fig. 1D). Hence, there is an antigenic difference between HI94TSV and BLZ02TSV within the VP1 region of the capsid protein that is recognized by MAb $1 \mathrm{~A} 1$.

\section{RT-PCR amplification and nucleotide sequencing of regions encoding VP1, VP2 and VP3}

The primers listed in Table 1 were used to amplify the VP coding regions of the TSV isolates. The sequencing of VP1 for the HI94TSV reference isolate (GenBank AF510518) was previously reported by Erickson et al. (2002), but none of the other VP regions from this isolate had been amplified previously. The expected bands were amplified from both isolates based on size estimates from the agarose gel of the products (data not shown). The nucleotide sequence of each VP fragment was sequenced and the sequences were deposited in GenBank (AY826051, AY826052, AY826053, AY826054, AY826055). The nucleotide sequences of the VP fragments from BLZ02TSV demonstrated between 95 and 99\% identity with HI94TSV VP fragments.

\section{Protein sequencing}

The $\mathrm{NH}_{2}$-terminal amino acids (aa) from the VP proteins of the BLZ02TSV isolate were sequenced. The first 12 aa of the BLZ02TSV and HI94TSV isolates were the same for VP1 (SKDRDMTKVNAY), VP2 (ANPVEIDNFDTT) and VP3 (AGLDYSSSDTST), confirming that the protein bands visualized by SDS-PAGE were indeed VP1, VP2 and VP3 for the 2 isolates. The remaining downstream aa sequences were derived from the nucleotide sequence for each VP. Fig. 3 shows the derived aa sequence for VP1 of BLZ02TSV compared with the HI94TSV reference sequence. The derived aa sequence of BLZ02TSV VP1 showed 96\% identity with the VP1 sequence of HI94TSV. The VP2 and VP3 derived aa sequences are not shown, but can be deduced from the GenBank nucleotide sequences. BLZ02TSV VP2 contained 3 aa substitutions compared to HI94TSV VP2, whereas BLZ02TSV VP3 was $100 \%$ identical to HI94TSV.

\section{DISCUSSION}

The comparison of a TSV isolate from Belize in 2002 with the Hawaii reference isolate demonstrated that the isolate from Belize is a unique variant of TSV. The BLZ02TSV isolate was identified as being TSV by several criteria: histological lesions and affected tissues were consistent with TSV infection of Penaeus vannamei; diagnostic RT-PCR primers for TSV (OIE 2003) amplified the correct-sized product; diagnostic lesions were detected with TSV-specific gene probes by ISH; purified virions resembled TSV in both size and shape. The BLZ02TSV isolate, however, displayed several characteristics that distinguished it from the reference

HI94TSV VP1
BLZ02TSV VP1
HI94TSV VP1
BLZ02TSV VP1
HI94TSV VP1
BLZ02TSV VP1
HI94TSV VP1
BLZ02TSV VP1
HI94TSV VP1
BLZ02TSV VP1
HI94TSV VP1
BLZ02TSV VP1
HI94TSV VP1
BLZ02TSV VP1
HI94TSV VP1
BLZ02TSV VP1

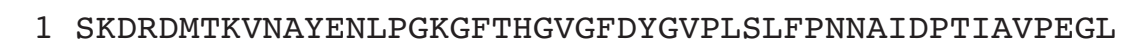

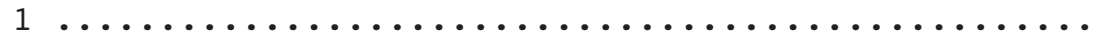

51 DEMSIEYLAQRPYMLNRYTIRGGDTPDAHGTIIADIPVSPVNFSLYGKVI

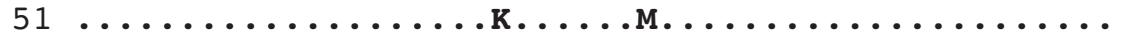

101 AKYRTLFAAPVSLAVAMANWWRGNINLNLRFAKTQYHQCRLLVQYLPYGS

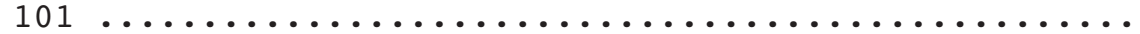

151 GVQPIESILSQIIDISQVDDKGIDIAFPSVYPNKWMRVYDPAKVGYTADC

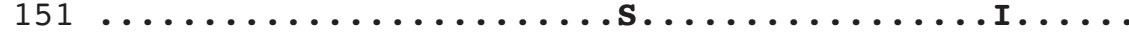

201 APGRIVISVLNPLISASTVSPNIVMYPWVNWSNLEVAEPGTLAKAAIGFN

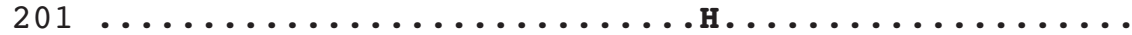

251 YPADVPEEPTFSVTRAPVSGTLFTLLQDTKVSLGEADGVFSLYFTNTTTG

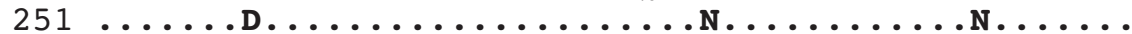

301 GRHRLAYAGLPGELGSCEIVKLPQGQYSIEYAATSAPTLVLDRPIFSEPI

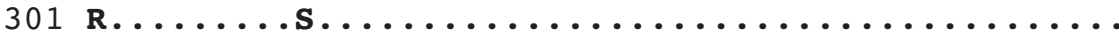

351 GPKYVVTKVKNGDVVGISEETLVTCGSMAAIGEATVAL

Fig. 3. Deduced amino acid (aa) sequence of VP1 from BLZ02TSV isolate (GenBank AY826051) compared to VP1 from reference HI94TSV isolate (GenBank AF510518). Single letter aa code is shown for HI94TSV; dots indicate identity with HI94TSV sequence; differences in code are in boldface 
isolate obtained from Hawaii in 1994. Differences were seen in the disease severity in susceptible $P$. vannamei and in the reactivity of the virus to the commercially available monoclonal antibody MAb 1A1. When bioassays were performed using tissue infected with BLZ02TSV, mortalities began to occur as early as Day 1 post-infection and generally were at least $1 \mathrm{~d}$ earlier than in control shrimp infected with HI94TSV (5/8 bioassays). Additionally, infection with BLZ02TSV resulted in $90-100 \%$ mortality in all but 1 bioassay experiment compared to $30-80 \%$ mortality in shrimp infected with HI94TSV. The bioassay results corroborate industry reports that describe TSV from Belize as being a more virulent strain of the virus.

By SDS-PAGE analysis, BLZ02TSV was shown to possess 3 major structural proteins consistent with the pattern seen with HI94TSV. Notably, no reaction was seen with VP1 from BLZ02TSV when the separated proteins were reacted with MAb 1A1 in a Western blot. The lack of reactivity to MAb 1A1 was also seen in IHC tests, wherein MAb 1A1 failed to react to TSV lesions in tissue sections from BLZ02TSV-infected shrimp. Therefore, the antigenicity of the VP1 protein from BLZ02TSV differs from that of the VP1 of HI94TSV. A TSV isolate from Sinaloa, Mexico, in 1998 (SIN98TSV) was similarly shown not to react with MAb $1 \mathrm{~A} 1$ in Western blots or IHC (Erickson et al. 2002). A TSV isolate from Sonora, Mexico, and an isolate from Nicaragua were also shown by Robles-Sikisaka et al. (2002) not to react with MAb 1A1 in IHC. Taken together, these results indicate that caution must be used when diagnosing TSV using serological tests that incorporate MAb $1 \mathrm{~A} 1$.

In order to further elucidate the differences in the BLZ02TSV isolate, the genes encoding the viral coat proteins were amplified and sequenced. The starting points of the coding regions for each VP of BLZ02TSV were confirmed by direct $\mathrm{NH}_{2}$-terminal aa sequencing of the proteins and all the proteins were shown to be identical to the HI94TSV proteins in their first 12 aa. Primers for VP1 started approximately $30 \mathrm{bp}$ upstream from the first codon of VP1 and ended $100 \mathrm{bp}$ prior to the start of VP3. VP2 primers started $100 \mathrm{bp}$ upstream of the first codon of VP2 and ended 75 bp prior to the start of VP1. VP3 primers started $100 \mathrm{bp}$ upstream of the VP3 start codon and ended at the stop codon for ORF2. These primers differ significantly from those utilized by Robles-Sikisaka et al. (2002) in their analysis of TSV geographic isolates, but the VP1 primers are identical to those used in the phylogenetic analysis by Tang et al. (2004). When the BLZ02TSV VP1, VP2 and VP3 coding regions were compared to the nucleotide sequence for these regions in HI94TSV, VP1 showed the most variability, although similarities for all regions were in the range of 96 to $100 \%$. When Tang et al.
(2004 and pers. comm.) compared VP1 from 29 TSV isolates from the Americas and Asia, they demonstrated that the BLZ02TSV isolate, as well as 2 other isolates from Belize in 2003 and 2004, are distinct from all the other isolates of TSV studied to date.

The data presented here indicate the presence of a new variant of TSV. It is not surprising that TSV, a single stranded RNA virus that infects thousands of individuals in each epizootic, has demonstrated mutations in the structural protein region. These changes are significant from a diagnostic standpoint since they are manifested by a loss of reactivity to the only monoclonal antibody available for testing. The data corroborates conclusions made by others (Erickson et al. 2002, Robles-Sikisaka et al. 2002) that MAb 1A1-based methods may not detect all TSV isolates and highlights the need to use more than 1 test prior to reporting the diagnosis of a particular disease. It is noteworthy that the OIE-designated TSV-specific primers and the gene probe for ISH (OIE 2003) have detected all suspected isolates of TSV studied to date at the UAZ Aquaculture Pathology Laboratory and hence may be the most useful as confirmatory tests for the presence or absence of TSV in clinical specimens.

Acknowledgements. Support for this research was provided by the Gulf Coast Research Laboratory Consortium Marine Shrimp Farming Program, CSREES, under grant no. 9938808-7431 and by a grant from the National Fisheries Institute. Special thanks to Wallace Clark at the UAZ Laboratory for Protein Sequencing and Analyses, to David Bentley for assistance with TEM and to Carlos Pantoja, Leone Mohney, Solangel Navarro, Rita Redman, Paul Schofield and Brenda Nobel at the UAZ Aquaculture Pathology Laboratory (Tucson, Arizona, USA) for their valuable input and assistance.

\section{LITERATURE CITED}

Alday de Graindorge V (2003) Shrimp virus biology helps explain viral activity. Glob Aquacult Advocate 6:85

Bell TA, Lightner DV (1988) A handbook of normal penaeid shrimp histology. World Aquaculture Society, Baton Rouge, LA

Bonami JR, Brehelin M, Mari J, Trumper B, Lightner DV (1990) Purification and characterization of IHHN virus of penaeid shrimps. J Gen Virol 71:2657-2664

Bonami JR, Hasson KW, Mari J, Poulos BT, Lightner DV (1997) Taura syndrome of marine penaeid shrimp: characterization of the viral agent. J Gen Virol 78:313-319

Chien T, Hsu-Tien H, Sheng-Hsiung C, Jung-Ping H and 5 others (1999) Taura syndrome in Pacific white shrimp Penaeus vannamei cultured in Taiwan. Dis Aquat Org 38: $159-161$

Erickson HS, Zarain-Herzberg M, Lightner DV (2002) Detection of Taura syndrome virus (TSV) strain differences using selected diagnostic methods: diagnostic implications in penaeid shrimp. Dis Aquat Org 52:1-10

Hasson KW, Lightner DV, Poulos BT, Redman RM, White BL, Brock JA, Bonami JR (1995) Taura syndrome in Penaeus vannamei: demonstration of a viral etiology. Dis Aquat 
Org 23:115-126

Holthius LB (1980) Shrimps and prawns of the world: an annotated catalogue of species of interest to fisheries. FAO species catalog. FAO Fisheries Synopsis 125(1). Food and Agriculture Organization of the United Nations, Rome

Jimenez R (1992) Síndrome de Taura (Resumen) Acuacultura del Ecuador. Rev Espec Cámara Nac Acuacult Guayaquil $1: 1-16$

Laemmli UK (1970) Cleavage of structural proteins during the assembly of the head of bacteriophage T4. Nature 227: 680-685

Lien TW, Hsiung HC, Huang CC, Song YL (2002) Genomic similarity of Taura syndrome virus (TSV) between Taiwan and western hemisphere isolates. Fish Pathol 37:71-75

Lightner DV, Redman RM, Hasson KW, Pantoja CR (1995) Taura syndrome in Penaeus vannamei (Crustacea: Decapoda): gross signs, histopathology and ultrastructure. Dis Aquat Org 21:53-59

Lotz JM (1997) Special topic review: viruses, biosecurity and specific pathogen-free stocks in shrimp aquaculture. World J Microbiol Biotechnol 13:405-413

Mari J, Bonami JR, Lightner DV (1998) Taura syndrome of penaeid shrimp: cloning of viral genome fragments and development of specific gene probes. Dis Aquat Org 33: 11-17

Mari J, Poulos BT, Lightner DV, Bonami JR (2002) Shrimp Taura syndrome virus: genomic characterization and similarity with members of the genus Cricket paralysis-like viruses. J Gen Virol 83:915-926

Matsudaira P (1987) Sequence from picomole quantities of proteins electroblotted onto polyvinylidene difluoride membranes. J Biol Chem 262:10035-10038

Mayo MA (2002a) A summary of taxonomic changes recently approved by ICTV. Arch Virol 147:1655-1656

Mayo MA (2002b) ICTV at the Paris ICV: results of the plenary session and the binomial ballot. Arch Virol 147: 2254-2260

Nakamura K, Tanaka T, Kuwahara A, Takeo K (1985) Microassay for proteins on nitrocellulose filter using protein dye-staining procedure. Anal Biochem 148:311-319

Nielsen BL, Brown LR (1984) The basis for colored silverprotein complex formation in stained polyacrylamide gels. Anal Biochem 141:311-315

Nunan LM, Poulos BT, Lightner DV (1998) Reverse transcrip-

Editorial responsibility: Timothy Flegel,

Bangkok, Thailand tion polymerase chain reaction (RT-PCR) used for the detection of Taura syndrome virus (TSV) in experimentally infected shrimp. Dis Aquat Org 34:87-91

OIE (Office Internationales Epizooties) (2003) Taura syndrome virus. In: Diagnostic manual for aquatic animal diseases, 4th edn, Chapter 4.1.1. OIE, Paris

Pantoja CR, Navarro SA, Naranjo J, Lightner DV, Gerba C. (2004) Non-susceptibility of primate cells to Taura syndrome virus. Emerg Infect Dis 10:2106-2212

Poulos BT, Kibler R, Bradley-Dunlop D, Mohney LL, Lightner DV (1999) Production and use of antibodies for the detection of Taura syndrome virus in penaeid shrimp. Dis Aquat Org 37:99-106

Poulos BT, Pantoja CR, Bradley-Dunlop D, Aguilar J, Lightner DV (2001) Development and application of monoclonal antibodies for the detection of white spot syndrome virus of penaeid shrimp. Dis Aquat Org 47:13-23

Robles-Sikisaka R, Hasson KW, Garcia DK, Brovont KE, Cleveland KD, Klimpel KR, Dhar AK (2002) Genetic variation and immunohistochemical differences among geographic isolates of Taura syndrome virus of penaeid shrimp. J Gen Virol 83:3123-3130

Rosenberry B (2002) World shrimp farming 2002, No. 15. Shrimp News International, San Diego, CA

Tang KFJ, Poulos BT, Lightner DV (2004) Genetic variation between isolates of Taura syndrome virus from different geographic regions. Aquaculture 2004, Book of Abstracts, World Aquaculture Society, Baton Rouge, LA, p 576

Tu C, Huang HT, Chuang SH, Hsu JP and 5 others (1999) Taura syndrome in Pacific white shrimp Penaeus vannamei cultured in Taiwan. Dis Aquat Org 38:159-161

White BL, Schofield PJ, Poulos BT, Lightner DV (2002) A laboratory challenge method for estimating Taura syndrome virus resistance in selected lines of Pacific white shrimp Litopenaeus vannamei. J World Aquacult Soc 33:341-348

Wyban JA, Swingle JS, Sweeney JN, Pruder GD (1992) Development and commercial performance of high health shrimp using specific pathogen free (SPF) broodstock Penaeus vannamei. In: Wyban J (ed) Proceedings of the Special Session on Shrimp Farming. World Aquaculture Society, Baton Rouge, LA, p 254-259

Yu CI, Song YL (2000) Outbreaks of Taura syndrome in Pacific white shrimp Penaeus vannamei cultured in Taiwan. Fish Pathol 35:21-24

Submitted: April 7, 2004; Accepted: December 17, 2004

Proofs received from author(s): March 7, 2005 